\title{
Ensino híbrido utilizando a Rede Social Edmodo: um estudo exploratório sobre as potencialidades educacionais para o Ensino de Química
}

\section{RESUMO}

Bruno Silva Leite brunoleite@ufrpe.br 0000-0002-9402-936X

Universidade Federal Rural de Pernambuco - UFRPE - Brasi

\begin{abstract}
A Rede Social Edmodo (RSE) possui características próprias e específicas que promovem mudanças no comportamento de professores e estudantes. A pesquisa relata a experiência de 27 professores de química do ensino básico/superior e de 131 estudantes do curso de licenciatura em química, apropriando-se da RSE. O uso da RSE por esses professores ocorreu por meio do modelo de ensino híbrido. Através deste modelo, os estudantes realizaram as atividades durante a disciplina. Os resultados coletados no estudo apontam para uma postura favorável dos professores e alunos frente à utilização do Edmodo em sala de aula. Princípios do conectivismo, aprendizagem conectada e da Teoria da Distância Transacional são observados. Concluímos que o uso da RSE, incorporado a estratégias no ensino híbrido, tem grande potencial para auxiliar no processo de ensino e aprendizagem, além de ser um ambiente virtual gratuito em que a interação entre o professor e os alunos é acentuada.
\end{abstract}

PALAVRAS-CHAVE: TIC. Rede Social. Ensino Híbrido. Edmodo. 


\section{INTRODUÇÃO}

A necessidade de um maior envolvimento da sociedade nos dias atuais quando discutimos sobre os aspectos da comunicação e aprendizagem por meio das Tecnologias da Informação e Comunicação (TIC), tem proporcionado boas perspectivas e esperança no âmbito educacional. Percebe-se que a cada dia as TIC são incorporadas como recursos didáticos digitais no processo pedagógico (LEITE, 2015). Essa utilização necessita ser acompanhada por um amplo processo, que envolve discussões teóricas e práticas de todos os participantes. Devemos entender que as tecnologias devem ser introduzidas a partir de três pilares: Adição, Estratégias e Realidade. Esses três pilares são fundamentais para qualquer discussão sobre a introdução das tecnologias no ensino. Cabe ressaltar, que a utilização das TIC, dentre elas a Internet em especial, vêm se apresentando como ferramenta bastante acionada na construção do conhecimento (LEITE; LEÃO, 2015) e é fundamental a adequação da escola, dos professores e dos alunos ao bom uso da mesma.

As tecnologias possibilitam novas perspectivas nas relações entre professores e estudantes, revisitando o papel da escola como um meio social. Para Mercado (1999), ao diversificar os espaços de construção do conhecimento, as tecnologias revolucionam os processos e metodologias de aprendizagem, além disso, facilitam o diálogo entre a escola e a sociedade. Assim podemos verificar que a utilização das tecnologias nas práticas docentes tem crescido na última década, como consequência das propostas de incentivo à sua inserção no ambiente educacional (SOUZA; SCHNEIDER, 2016).

Nesse contexto, as redes sociais possibilitam uma nova forma de organização da sociedade, que é ao mesmo tempo virtual e atual, dando a possibilidade de se criar vínculos sem limites geográficos e atemporais, enquanto libera o indivíduo para criar seu próprio conteúdo e difundir suas ideias através de seus laços eletrônicos de amizade com uma facilidade e velocidade incríveis, pois elas "representam uma nova tendência de compartilhar contatos, informações e conhecimentos" (LEITE, 2015, p. 261). Pereira e Benite (2012) relatam que as redes sociais foram foco de pesquisas empíricas e teóricas nas ciências sociais durante 50 anos, devido ao interesse sobre os padrões de interação humana, acreditando que esses padrões têm implicações importantes para a expansão de informação. Atualmente, as Redes Sociais na Internet têm sido o ambiente mais comum para as interações entre a sociedade. Não é estranho ouvir falar de Facebook, Twitter, Google+, entre outros. A extraordinária capacidade de se comunicar com as redes sociais tem proporcionado a um grande número de pessoas utilizarem essas redes com diversos fins, por exemplo, para encontrar e conversar com amizades perdidas com o tempo, para debater sobre os temas mais variados, divulgar eventos e congressos, apoiar movimentos e causas de todos os tipos, organizar encontros de amigos e ex-companheiros de estudos. Observa-se que a literatura apresenta discussões sobre o uso das tecnologias no ensino de química (EICHLER et al., 2003; ARROIO; GIORDAN, 2006; BENITE; BENITE, 2008; SOUZA et al., 2011; LEITE, 2014) porém, quando tratamos de redes sociais no ensino de Química (RAUPP; EICHLER, 2012; VAZ; SOARES, 2014) como tecnologias de ensino, pouco se tem discutido.

Diante deste quadro, o ambiente educacional não deve se afastar dos acontecimentos sociais, que mudam a forma de comunicação entre as pessoas. 0 potencial comunicador das redes sociais sem dúvida deve ser estudado com mais 
afinco. As redes sociais são estruturas compostas por pessoas ou por entidades humanas, na qual estão conectadas por uma ou várias relações que podem ser de amizade, trabalho, intercâmbios econômicos ou qualquer outro interesse. Neste trabalho, nosso foco está em discutir alguns métodos de utilização de uma rede social para promover a aprendizagem centrada no aluno e motivá-los ao trabalho coletivo e autônomo. No desenvolvimento desta pesquisa, no período de estudos da disciplina utilizou-se a Rede Social Edmodo (RSE) como recurso para contribuir no processo de ensino e aprendizagem de química.

\section{TEORIAS DA APRENDIZAGEM EM REDE}

O ambiente virtual apresenta muitas características, nas quais questionam-se quais teorias podemos utilizar como suporte para a aprendizagem em rede? Percebe-se que existem diversas teorias que podem ser utilizadas como base teórica, entretanto algumas delas estão intrinsicamente ligadas as contribuições que as tecnologias proporcionam no ensino. Para esse estudo, consideramos três teorias que contemplam alguns aspectos observados durante a pesquisa, contudo, não queremos inferir que essas teorias são absolutas para esses ambientes e que outras teorias não poderiam ser utilizadas.

A primeira delas o conectivismo (ou aprendizagem distribuída) é proposto como uma teoria mais adequada para a era digital, "quando a ação é necessária sem aprendizagem pessoal, utilizando as informações fora do nosso conhecimento primário" (LEITE, 2014). É também considerada como a terceira geração de pedagogia da educação à distância (ANDERSON; DRON, 2011). O conectivismo, proposto por Siemens (2004), é considerado como uma teoria de aprendizagem para a era digital, devido ao fato de como ela tem sido utilizada para explicar o efeito que a tecnologia tem sobre a forma como as pessoas vivem, como se comunicam, e como aprendem. Quando a aprendizagem ocorre como parte de uma rede social, ela é chamada de conectivismo. O ponto de partida do conectivismo é o indivíduo (SIEMENS, 2004). O mesmo é guiado pela noção de que as decisões são baseadas em princípios que estão mudando rapidamente, continuamente se está adquirindo novas informações (LEITE, 2014). O conectivismo espera que o processo de aprendizagem dos estudantes na era digital seja bem-sucedido. Alguns princípios do conectivismo propostos por Siemens (2004) são descritos a seguir:

I. Aprendizagem e conhecimento apoiam-se na diversidade de opiniões e posições, e permite a seleção do melhor enfoque;

II. O conhecimento reside nas redes e a aprendizagem é ativada/facilitada pela tecnologia;

III. Aprender e conhecer são processos contínuos em curso (não estados definitivos ou produtos).

IV. Conhecimento atualizado e exato é o propósito de todas as atividades conectivistas de aprendizagem;

V. Aprender é tomar decisões. $\mathrm{O}$ ato de escolher o que quer aprender e o significado da informação que se recebe, é visto através da lente de uma realidade em mudança. Uma decisão correta hoje pode estar 
equivocada amanhã, devido a alterações no ambiente informativo que afeta a decisão.

O professor, no conectivismo, não é considerado o único responsável por definir, gerar ou organizar o conteúdo, pois conta também com a colaboração dos estudantes (MATTAR, 2013). A aprendizagem ocorre distribuída dentro de uma rede social, tecnologicamente avançada, reconhecendo e interpretando padrões (LEITE, 2014).

Além do conectivismo como teoria utilizada para a era digital, observamos os contributos da Teoria da Aprendizagem Conectada (Connected Learning) que propõe um tipo de aprendizagem que integra interesse pessoal, as relações entre colegas, e realização em áreas acadêmicas, cívicas, ou relevantes para a carreira (ITO et al., 2013). A aprendizagem conectada é uma abordagem para a reforma educacional com chave para a abundância de informação e social conexão provocada pelos meios de comunicação em rede e digitais. 0 termo "Aprendizagem Conectada" é utilizado em pesquisas desde o início da década de 1990 (SCHWARTZ, 1991; LUNDEBERG; MOCH, 1995). A partir de 2000, esse termo começou a ser usado em publicações de pesquisas para referir-se aos diversos projetos baseados nas redes sociais e de aprendizagem da era da informação (LEITE, 2015). Os defensores dessa teoria postulam que essa abordagem utiliza novos meios de comunicação para ampliar o acesso a oportunidades e experiências de aprendizagem significativas (ITO et al., 2013; CORNWELL; CORNWELL, 2006). Assim, a aprendizagem conectada aproveita os avanços da era digital conectando acadêmicos aos seus interesses, alunos inspirados em seus pares e mentores. O modelo dessa aprendizagem sugere que os jovens aprendam melhor quando: (1) Eles estão interessados em que eles estão aprendendo; (2) Eles têm seus pares e mentores que compartilham esses interesses; (3) Seu aprendizado é direcionado para oportunidades e reconhecimento (ITO et al., 2013; CORNWELL; CORNWELL, 2006). Os ambientes que apoiem a aprendizagem conectada são geralmente caracterizados como tendo um sentido de propósito comum, um foco na produção e infraestruturas em rede aberta.

Assim, essa aprendizagem é baseada no seguinte conjunto de princípios (CORNWELL; CORNWELL, 2006, p.19): (a) O processo de educação deve tornar-se centrado no aluno; (b) Avaliação - diagnóstica, formativa e somativa - deve ser melhorada e profundamente integrada no processo de ensino e aprendizagem; (c) Padrões acadêmicos nacionais e estaduais devem ser atingidos ou excedidos; (d) A aprendizagem deve se tornar mais ativa; (e) A formação de comportamentos de aprendizagem ao longo da vida deve ser facilitada; (f) A reforma da educação deve ser guiada pelo empirismo; (g) Ensino e aprendizagem de conteúdos devem ser da mais alta qualidade possível, atual e relevante; (h) Comprovadas metodologias pedagógicas e as melhores pesquisas de todas as áreas (i) que se referem à aprendizagem e ensino devem ser integradas na educação; (j) Sempre que existem padrões mínimos, o objetivo deve ser o domínio próximo ao universal, em vez de uma distribuição normal de realização.

E por fim, consideramos a Teoria da Distância Transacional (TDT) proposta por Moore (1993), em que a transação a que chamamos Ensino à Distância ocorre entre indivíduos, mestres e aprendentes, num ambiente que possui característica especial de ambos estarem separados um do outro. A teoria da distância transacional é bastante acionada quando tratamos sobre ambientes virtuais de aprendizagem. O conceito de transação tem origem em Dewey (DEWEY; BENTLEY, 
1949). Para o Moore (1993) a distância transacional é uma função de duas variáveis: diálogo e estrutura. A capacidade de comunicação entre o aluno e o professor está relacionada com o diálogo, já a estrutura provém das necessidades individuais do aluno em resposta a um programa. Segundo Moore (1993), parece existir "uma relação entre diálogo, estrutura e autonomia do aluno, pois quanto maior a estrutura e menor o diálogo em um programa, maior autonomia o aluno terá de exercer". Nos ambientes virtuais de aprendizagem o ensino ocorre como "um processo colaborativo que reúne em equipes de planejamento e redes de distribuição a competência de um certo número de especialistas" (MOORE, 1993), e dificilmente como um ato individual.

Esta teoria apresenta discussões sobre aspectos importantes da relação entre ensino e aprendizagem, em ambientes virtuais, a saber: autonomia, motivação e interação. Moore (1993) considera o grau de autonomia do aluno como sendo a medida pela qual ele mesmo determina os seus objetivos, suas experiências de aprendizagem e suas decisões. A motivação está relacionada ao esforço em relação a qualquer objetivo, sendo a responsável pela intensidade, direção e persistência dos esforços de uma pessoa para o alcance de uma determinada meta. Por fim, temos a Interação, que pode ser observada em três formas: interação alunoconteúdo, que visa um processo de aprendizado planejado e mediado, no qual o aluno autonomamente elabora sua própria aprendizagem por processos de internalização de informações em estruturas cognitivas já existentes, interagindo e transformando o conteúdo em conhecimento individual; A interação alunoprofessor ocorre quando o professor interage com o aluno motivando e instigando o interesse pelo conteúdo discutido, incentivando a participação, considerando a diversidade e respeitando as individualidades, além de "ajudar os alunos a aplicar aquilo que estão aprendendo, à medida que colocam em prática aptidões que viram ser demonstradas ou manipulam informações e ideias que foram apresentadas" (MOORE; KEARSLEY, 2007, p. 152); Já a interação entre aluno-aluno, podendo acontecer de diferentes formas, por exemplo, por chat e/ou mensagem de texto.

Ressaltamos que o uso dessas teorias nessa pesquisa é justificado por elas darem suporte as atividades propostas e apresentarem percepções sobre o uso do instrumento de pesquisa.

\section{REDE SOCIAL EDMODO}

Existem vários recursos das TIC que podem ser utilizados no processo de aprendizagem, essas características proporcionam atração para os alunos e pode ser usado para ensinar as quatro habilidades linguísticas: ouvir, ler, falar e escrever. A Rede Social Edmodo ${ }^{1}$ pode ser considerada um recurso para utilizar essas quatro habilidades. Ela está baseada na Web 2.0, e tem como finalidade permitir a comunicação entre professores e alunos. O Edmodo surgiu em 2008 com o objetivo de ser uma ponte entre como os alunos viviam suas vidas e como eles aprendiam na escola (LEITE, 2015). Sendo esta concebida com objetivos educacionais, possibilitando a conexão entre professores, alunos e pais. Souza e Schneider (2016, p. 422) defendem que, a relevância de aliar as práticas de ensino às redes sociais se dá por conta de sua capacidade em "romper barreiras e 
reafirmar a aprendizagem que pode acontecer em espaços variados e a todo o tempo, e não exclusivamente na sala de aula". O Edmodo é um serviço de Rede Social cujo objetivo é oferecer um ambiente virtual fechado conversacional, tratase de uma plataforma de e-learning com características de uma rede social. Além disso, o Edmodo é gratuito para toda comunidade escolar, podendo ser utilizado por meio dos dispositivos móveis. Ele é dedicado à educação em todos os graus, jardim de infância, ensino fundamental, médio e educação superior, além de possibilitar seu uso fora das paredes físicas das salas de aula. A interface do Edmodo lembra a do Facebook deixando o usuário familiarizado com ele. Existem várias características Edmodo que podem ser utilizados para ensinar.

$\mathrm{Na}$ Rede Social Edmodo os professores podem anexar arquivos, enviar materiais de leitura em forma de .txt, .doc ou PDF. Os estudantes podem fazer o download ou pré-visualizar e postar respostas para enriquecer a sua compreensão. É possível pontuar os estudantes diretamente por tarefa, e eles podem ver sua própria nota na página de atribuição. A pontuação total de cada estudante é contada automaticamente pelo Edmodo, ele dá aos professores uma grande economia de tempo na correção das atividades e de apoio à gestão da aula.

No ambiente do Edmodo é possível realizar algumas funções, tais como: Anotação, Alerta, Enquetes, Quiz, Tarefas, Reação, Calendário. Além de fornecer recursos que permitem os alunos trabalharem em grupo, o Edmodo permite conectar com outros professores que estão ensinando os mesmos tópicos, tornando mais fácil de encontrar o conteúdo para usar em sala de aula. O recurso Insights, contribui no feedback dos alunos e o fluxo de Atividade fornece uma visão em tempo real de todas as atividades dos alunos e conexões. Possibilita que os pais possam acompanhar as atividades dos filhos. Para isso é fornecido um código que identifica o aluno. $O$ envolvimento dos pais dá uma grande motivação para escrever mais e fazer melhor, porque os alunos sabem que os pais vão ler e ver seu trabalho (ROBLYER, 2006). É importante destacar que ao trabalhar com os alunos o Edmodo oferece a possibilidade dos pais monitorarem as atividades que os alunos realizam e assim trabalhar em parceria com o docente no monitoramento das atividades e também promove um bom relacionamento entre os pais, professores e alunos.

Pontuamos que o Edmodo apresenta características de ferramentas da Web 2.0, como a de "oferecer ao professor aplicações uteis, gratuitas, colaborativas e simples de usar" (LEITE; LEÃO, 2015, p. 295), além dos princípios do conectivismo estarem presentes em sua concepção. A facilidade que os alunos têm em utilizar as redes sociais é um fator primordial para a determinação da satisfação e sucesso em atividades envolvendo tecnologias. Observamos que a RSE se constitui também em um ambiente virtual de aprendizagem, suportado por características da Educação a Distância (EaD), uma "modalidade educacional na qual a mediação didático-pedagógica nos processos de ensino e aprendizagem ocorre com a utilização de meios e tecnologias de informação e comunicação, com estudantes e professores desenvolvendo atividades educativas em lugares ou tempos diversos" (BRASIL, 2005). Na RSE a Teoria da Distância Transacional é evidenciada, tanto nos aspectos de Motivação e autonomia, bem como nas interações aluno-conteúdo, professor-aluno, aluno-aluno, sendo possível também interações professorprofessor e professor-pais. 


\section{ENSINO HÍBRIDO}

A tradicional sala de aula presencial e o ambiente virtual sempre gerou atenção dos seus usuários, embora tenham desenvolvido modelos de aprendizagem separadamente, podemos observar que podem ser mutualmente complementares. Segundo Tori (2009), a convergência desses dois ambientes de aprendizagem tem como resultado os cursos híbridos, que procuram aproveitar as vantagens presentes em cada modalidade de ensino. Com esses cursos híbridos, é possível utilizar uma maior quantidade de recursos de aprendizagem, planejando atividades presenciais ou virtuais. Através da portaria no 2.253, de 18 de outubro de 2001, foi possível que as instituições de ensino permitissem a inclusão de até $20 \%$ da carga horária do curso para atividades não presenciais (BRASIL, 2001), o que contribuiu para o crescimento desses cursos híbridos.

O termo ensino híbrido (blended learning) em alguns casos tem sua definição incoerente por algumas interpretações distintas. Horn e Staker (2015) após investigarem por cinco anos os programas de ensino híbrido apresentam uma definição em três partes: por meio do ensino on-line, em um local físico supervisionado e uma experiência de aprendizagem integrada. Nesse sentido, o ensino híbrido é considerado qualquer programa educacional formal no qual um estudante constrói sua aprendizagem, pelo menos uma parte, por meio do ensino on-line em que o mesmo tenha controle de algum elemento (tempo, lugar ou ritmo). É também quando o estudante aprende, pelo menos em parte, em um local físico supervisionado longe de casa. A terceira parte da definição descreve que as modalidades, ao longo do percurso percorrido para a aprendizagem de cada estudante, quer seja em uma disciplina ou curso, estão conectadas para fornecer uma experiência de aprendizagem integrada. A figura 1 representa de maneira simples a convergência entre aprendizagem virtual e a aprendizagem presencial, gerando o que conhecemos por Ensino Híbrido.

Figura 1 - Representação do surgimento do Ensino Híbrido originado pela convergência entre a aprendizagem presencial e virtual.

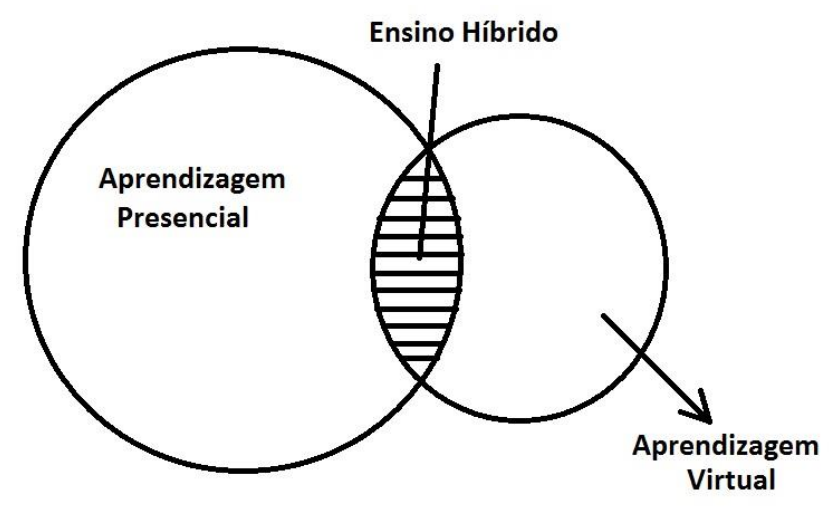

(Fonte: Própria)

O crescimento do ensino híbrido pode gerar rupturas na dicotomia da distância na educação, a qual vai de um nível de proximidade zero (atividade totalmente a distância) à máxima proximidade, em função das dimensões tempo, espaço e interatividade (TORI, 2009). O ensino híbrido busca o equilíbrio entre o ensino presencial e o ensino a distância, a partir de metodologias e práticas pedagógicas que proporcionem o desenvolvimento cognitivo dos estudantes, 
apropriando-se do uso das tecnologias digitais e dos momentos presenciais. Numa perspectiva construtivista, Grahan (2006) identifica seis razões para a utilização do ensino híbrido: riqueza pedagógica, acesso ao conhecimento, interação, personalização, custos e facilidade de revisão.

Nesse contexto, o Edmodo pode ser utilizado por meio da prática do aprendizado combinado, que refere-se à combinação da educação a distância e da instrução em sala de aula (BONK; GRAHAM, 2006) e pelo ensino híbrido que é um programa de educação formal, no qual um estudante aprende, pelo menos em parte, por meio de ensino on-line (HORN; STAKER, 2015). É importante destacar que $o$ aprendizado combinado normalmente envolve diversas aulas presenciais que são complementadas com o uso da web e que no ensino híbrido o estudante aprende, pelo menos em parte, em um local físico supervisionado longe de casa, proporcionando uma experiência de aprendizagem integrada. De forma geral, no aprendizado combinado a instrução em sala de aula pode ser considerada um instrumento combinado com a tecnologia para produzir um ambiente de aprendizado bem mais eficaz do que seria possível quando utilizamos apenas um dos dois recursos.

O aprendizado combinado é bastante popular na educação superior, já que permite que os professores deem continuidade à prática da instrução em sala de aula com a qual estão familiarizados e sentem-se confortáveis acrescentando o quanto de tecnologia desejarem (MOORE; KEARSLEY, 2013). O ensino híbrido enquadra-se dentro de quatro modelos principais (HORN; STAKER, 2015): Rotação (na qual inclui a "sala de aula invertida"), Flex, À la Carte e Virtual Enriquecido. O equívoco mais comum relacionado ao ensino híbrido é confundi-lo com ensino enriquecido por tecnologia. No ensino híbrido, os estudantes têm um domínio sobre o local que irá ocorrer sua aprendizagem, sobre o momento e sobre o ritmo de sua aprendizagem, enquanto que no ensino enriquecido por tecnologia, "as atividades de aprendizagem são padronizadas por toda a classe" (HORN; STAKER, 2015). Ademais, no ensino híbrido temos associados os pontos fortes do ensino presencial (interação, presença do professor) e do ensino a distância.

\section{METODOLOGIA}

O universo da pesquisa foi composto por 131 discentes das disciplinas de "Informática, Química e Educação (IQE)" e "Instrumentação para o Ensino de Química (IEQ)" do curso de licenciatura em Química durante os semestres 2015.1 (47 discentes), 2015.2 (55 discentes) e 2016.1 (29 discentes). Participaram 31 discentes da turma IQE e 16 da turma IEQ no semestre 2015.1, 36 discentes da turma IQE e 19 da turma IEQ no semestre 2015.2 e 22 estudantes da turma IQE e 7 da turma IEQ no semestre 2016.1. Esses discentes estudaram e utilizaram o Edmodo durante 12 horas/aula (aproximadamente 1/4 das aulas do semestre), propuseram situações em que poderiam utilizar o Edmodo em sala de aula por meio de um seminário individual e ao final da disciplina responderam ao questionário. $O$ questionário tinha como objetivo obter informações e opiniões dos alunos acerca do uso da RSE. O mesmo constou de 16 questões objetivas e subjetivas, sendo aplicado aos discentes do curso. As perguntas do questionário foram disponibilizadas online por meio do formulário do Google². Além disso, em nossa pesquisa participaram vinte e sete (27) professores do ensino básico e superior durante a capacitação realizada pelo pesquisador, contribuindo para uma 
análise do potencial de uso do Edmodo como ferramenta no processo de ensino e aprendizagem. A capacitação foi realizada durante a Jornada Virtual ABED de EAD realizada no segundo semestre de 2014. Esses professores se apropriaram do Edmodo em sua prática docente durante o semestre 2015.2 (exceto três professores que utilizaram o Edmodo com os discentes nas disciplinas mencionadas acima), após esse período eles responderam ao mesmo questionário dos discentes (que tinha como objetivo obter informações e opiniões em relação ao uso da RSE). A utilização do Edmodo pelos 24 professores no segundo semestre de 2015 se justifica ao fato dos mesmos necessitarem de tempo para prepararem suas atividades no ambiente.

Diante da necessidade de sustentar a coerência e a consistência entre os objetivos propostos e o trabalho investigativo como um todo, o desenvolvimento desta investigação seguiu os moldes de uma abordagem qualitativa de cunho descritivo, do tipo levantamento (RICHARDSON, 1999; GOLDENBERG, 2004; LÜDKE; ANDRÉ, 1986; COUTINHO, 2008; GIL, 2008). A abordagem qualitativa assume a construção social da realidade e nessa perspectiva, observamos a característica descritiva do tipo levantamento (COUTINHO, 2008). Considera-se descritiva por ter como objetivo descrever as características de determinado grupo (população). Nesse tipo de pesquisa evidenciam-se as que têm por objetivo estudar as características de um grupo, levantar opiniões e atitudes de uma população e possíveis associações entre variáveis pesquisadas. É do tipo levantamento devido aos questionamentos diretos aos indivíduos cujas representações se quer compreender. Esse tipo de pesquisa apresenta como escopo a busca em "resolver" o problema de pesquisa, analisando e registrando os fenômenos que envolvem o foco de pesquisa sem, entretanto, entrar no mérito de seu conteúdo por meio de intervenções do pesquisador (ROSA, 2012). Ademais, revela como característica a utilização de técnicas de coleta de dados padronizadas.

Com relação as atividades descritas pelos estudantes e professores, observase seu desenvolvimento como um estudo de caso, a fim de melhor elucidar a apropriação da Rede Social Edmodo como uma ferramenta didática no processo de ensino e aprendizagem de Química. A atividade foi dividida em três momentos, o primeiro consta da apresentação do Edmodo e de suas ferramentas. Este momento tinha o intuito de possibilitar aos estudantes e professores conhecerem a ferramenta e apropriassem dela. No segundo momento da atividade, os discentes apresentaram suas propostas para o uso do Edmodo por meio de um seminário individual. Esta etapa aspirava nos estudantes perspectivas em relação a suas futuras práticas docentes, levando em consideração o processo de formação inicial de cada indivíduo, identificando possíveis práticas inovadoras, consideradas por estes. Por fim, o terceiro momento consistiu na resolução do questionário. Para manter a fidedignidade das respostas, as transcrições realizadas nas questões subjetivas, são apresentadas conforme escrito pelos alunos e professores, preservando-se erros de redação de texto etc. ainda, para a identificação dos sujeitos, foram adotados nomes fictícios (independentemente de gênero) e eliminaram-se dados que poderiam identificar os sujeitos. Os alunos foram nomeados como A1, A2, A3, ..., A47 (para os alunos do semestre 2015.1), de A47 até A102 (para os alunos do semestre 2015.2) e A103 até A131 (para do semestre 2016.1). De maneira análoga, P1 foi o professor da disciplina IQE durante os semestres 2015.1 e 2016.1, P2, ministrou as disciplinas IQE em 2015.2 e IEQ no semestre 2016.1, já P3 lecionou a disciplina IEQ nos semestres 2015.1 e 2015.2, 
todas pertencentes a matriz do curso de Química da UFRPE, como disciplinas obrigatórias. Ademais, P4 à P27 são os professores do ensino básico e superior que participaram da capacitação e utilizaram o Edmodo em sua prática docente.

\section{RESULTADOS E DISCUSSÃO}

A seguir apresentamos alguns resultados da pesquisa referente as respostas dos professores que fizeram uso do Edmodo em sala de aula, apresentando sua perspectiva em relação à rede social Edmodo como uma ferramenta no processo de ensino e aprendizagem. Determinadas questões foram desconsideradas por não se aplicarem a atividade desenvolvida pelos professores. Também, é destacado as respostas dos discentes do curso de licenciatura em química, na qual utilizaram o Edmodo em uma disciplina do seu semestre letivo. Avaliamos que algumas respostas dos professores e estudantes podem ser compreendidas em conjunto, não havendo necessidade de distinções, outras respostas utilizamos as nomeações referente ao professor $(\mathrm{P})$ e ao aluno (A) para caracterizar nossas considerações. É importante considerar que o uso do Edmodo nessas turmas é identificado por meio da prática do aprendizado combinado e do Ensino Híbrido.

\section{ANÁLISE DOS DADOS OBTIDOS NAS RESPOSTAS DO QUESTIONÁRIO}

Em relação ao conhecimento sobre a plataforma Edmodo, 93,7\% responderam que não conheciam, sendo que todos os discentes afirmaram desconhecer, apenas alguns docentes $(37,0 \%)$ já conheciam o Edmodo. Quando questionados sobre a participação de atividades on-line, $79,7 \%$ dos participantes nunca tinham realizado algum tipo de atividade on-line. Reis (2009) descreve como atividade on-line, as estratégias que são mediadas pelo uso de ferramentas interativas, tais como chats, fóruns, e-mail. Ao serem indagados sobre "Qual sua opinião quanto a utilização do Edmodo?" tanto os docentes, quanto os discentes, julgaram o Edmodo como uma boa ferramenta, algumas das respostas são descritas a seguir: Para P3, o Edmodo é um "site muito bom para realizar as tarefas para nossos alunos, programando os períodos a serem exigidos deles, além de ser prático e simples de fazer" e P19 considera "Prático e útil, pois economiza o tempo da sala de aula para dar aulas e pode utilizar-se do Edmodo para realizações de tarefas, e assim deixar o conteúdo programado em dia com mais facilidade". Nessas respostas observamos algumas características de atividades realizadas em ambientes online descritas por Moore e Kearsley (2013). Outro professor relata que o Edmodo pode ser uma "alternativa interessante e dinâmica entre professor e aluno, promovendo interatividade" (P24), resposta essa que reflete uma das questões amplamente discutidas em ambientes $\mathrm{EaD}$, a interatividade (COSTA et al., 2015; BELUCE; OLIVEIRA, 2016; BROD; RODRIGUES, 2016). Já A7 afirma que

O Edmodo, é uma ferramenta que serve para desenvolver o conhecimento, de fundamental importância para se praticar o que foi visto nas aulas. Fácil de se manusear. Fixar bem o conteúdo através dos slides que podiam ser postados pelo professor e também nós alunos ganhamos tempo com isso já que tempo é algo precioso para cada um de nós alunos que prestamos vestibulares. A comunicação sempre foi rápida com relação aluno/professor. Assuntos podiam ser discutidos e dúvidas resolvidas. ÓTIMA FERRAMENTA. 
É muito bom pois incentiva o estudo em casa, é prático porque é só abrir o site do Edmodo e fazer a atividade solicitada, em caso de dúvida sobre o sistema do Edmodo é só perguntar para o Professor e outro ponto que vale a pena ressaltar é a possibilidade dos alunos poderem escrever alguma dúvida, sugestão, pedido pela página de postagens.

É importante destacar que alguns desses alunos compararam o Edmodo com o Facebook, por exemplo, "[...] é tipo um Facebook estudantil!" afirma A33. De fato a rede social Edmodo apresenta uma interface que lembra a do Facebook, deixando o usuário mais familiarizado com ele. Diante das respostas apresentadas pelos professores e pelos alunos, consideramos que o Edmodo configura uma alternativa para a realização de atividades assíncronas e síncronas complementando as discussões dos conteúdos em sala de aula. Nesse contexto, quando questionados em relação aos aspectos positivos e negativos na utilização do Edmodo, encontramos diversas opiniões favoráveis a esta rede. Dentre as respostas dos professores, boa parte consideraram a realização de atividades programadas como um dos aspectos positivos, "os pontos principais dessa utilização foram a 'antecipação' de assuntos que sem à ajuda do Edmodo não seria possível vermos todos os conteúdos do 3 o ano do ensino médio" (P26), "realizar atividades online, em um site fechado, com interação dos alunos" (P14), e "[...] uma forma de interagir com os alunos, por apresentar uma boa acessibilidade ao material discutido em sala de aula, além da disponibilização de materiais complementares a aula" (P2). Dentre os alunos, as respostas convergiam na comodidade de ter os conteúdos disponíveis na rede social Edmodo, facilitando sua aprendizagem, por exemplo, "podemos aprender de uma forma descontraída, podemos acessar em horários que temos disponibilidade" (A6), além de relatarem a interação a qualquer momento com o professor ("Um maior contato com o professor e uma forma mais casual de atividade extraclasse", A27). Como já destacado anteriormente, a interatividade entre o professor e os alunos no ambiente on-line apresenta-se como um dos pontos que potencializa a mediação pedagógica (BROD; RODRIGUES, 2016). Em relação aos aspectos negativos do Edmodo, apenas $7,6 \%$ dos professores e estudantes destacaram. Entre eles a dificuldade inicial em usar a plataforma e em anexar as atividades, foram as mais comuns. Hara e Kling (1999) relataram que atividades envolvendo alunos em ambientes virtuais eram causadas por três motivos: falta de feedback imediato do professor, instruções ambíguas de atribuições e problemas técnicos.

No questionamento sobre a interação no uso do Edmodo, o gráfico 1 apresenta os resultados das respostas dos estudantes.

Gráfico 1 - Respostas do questionário em relação a interação dos estudantes no uso do Edmodo. 


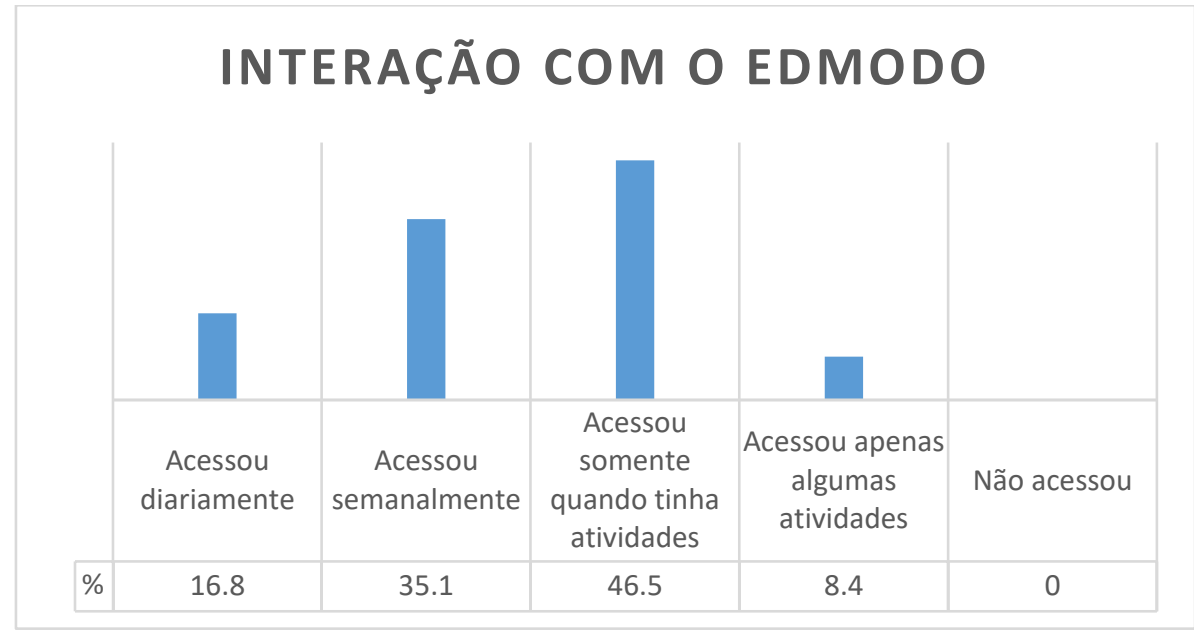

(Fonte: Própria)

As redes sociais na Internet têm possibilitado mais interações entre os professores e alunos. Contudo, observando os dados no gráfico 1 , os estudantes acessavam a plataforma, em sua maioria, quando existiam atividades para realizarem, ou seja, o nível de interação era reduzido - segundo a categorização hierárquica de Roblyer e Wiencke (2003). Nesse sentido, essas respostas nos levam a refletir sobre a importância do professor promover estratégias que possibilitem um maior envolvimento de seus alunos em atividades on-line, na qual pode conduzir aos três tipos de interação: interação entre o aluno e o conteúdo, interação entre o aluno e o instrutor, e interação aluno-aluno (MOORE, 1989; MOORE; KEARSLEY, 2013). Cada nível de interação é definido por fatores sociais, tecnológicos, de instrução, etc (ROBLYER; WIENCKE, 2003). Também no fórum, alguns professores identificaram o silêncio de muitos alunos, o que nos leva a afirmar a necessidade de um planejamento das atividades que proporcionem maiores interações entre os participantes. Acreditamos que o primeiro passo para que ocorram essas interações no ambiente on-line, o professor, além de proporcionar o intercâmbio de informações pessoais entre os alunos e incentivar a comunicação e a interação social, ele também deve interagir com os alunos, uma das características presentes na Teoria da Distância Transacional. Assegurar que exista um alto nível de interação e diálogo é uma estratégia valiosa para atividades em ambientes on-line.

Quando questionados sobre "Quais atividades você gostou de utilizar no Edmodo?", observamos que as "Tarefas" foram as mais aceitas tanto por estudantes $(88,5 \%)$ como por professores $(77,8 \%)$. A segunda atividade mais votada pelos discentes foi o Quiz $(58,0 \%)$ e as Enquetes $(62,9 \%)$ pelos docentes. Moore e Kearsley (2013) consideram que atividades com ênfase na comunicação assíncrona permitem um feedback ao professor podendo avaliá-las como satisfatória ou não em sua proposta pedagógica. Atividades mais estruturadas, como questionários, simulações, uso de mídias, entre outros, alcançam resultados importantes quando elaboradas adequadamente, elas são a fonte dos sinais de feedback que devem conduzir o processo de ensino e aprendizagem. Ainda sobre as atividades, os dados revelam que há divergência entre os professores e alunos quanto ao uso do Edmodo. Para 96,9\% dos estudantes as atividades no Edmodo devem ser realizadas como complementares, diferenciando da opinião dos professores $(59,2 \%)$. Os professores consideram que as atividades no Edmodo 
devem, em sua maioria $(81,5 \%)$, serem realizadas como atividades obrigatórias, opinião diferente da dos discentes $(37,4 \%)$. Os resultados da pesquisa também revelam que, na opinião dos participantes, é preciso tempo para a organização de atividades no ambiente do Edmodo (98,5\% dos estudantes e $85,2 \%$ dos professores). Essas perspectivas são distintas, pois para o professor o tempo para a realização de atividades no Edmodo é referente a criação de tais atividades, envolvendo quais objetivos, o que se quer obter com a atividade, etc. Já para os estudantes referem-se ao tempo para a realização da atividade.

Sobre a usabilidade destacamos separadamente as respostas dos estudantes que utilizaram o Edmodo e dos professores, que nesse caso, comportaram-se tanto como instrutores, bem como gestores, auxiliando no processo de ensino e aprendizagem de seus alunos. Em relação ao acesso, 91,6\% dos estudantes afirmaram terem conseguido acessar todo o conteúdo, apenas 10,7\% tiveram dificuldades em encontrar os links na RSE e $95,4 \%$ consideraram importante o acompanhamento do professor da disciplina durante o uso do Edmodo. É importante destacar o papel do professor no acompanhamento do aluno durante atividades on-line, considerando os objetivos de aprendizado, o gerenciamento dos trabalhos realizados pelos alunos e como analisa os resultados alcançados (MOORE; KEARSLEY, 2013). Em relação aos docentes participantes da pesquisa, para esse mesmo questionamento, todos conseguiram acessar plenamente a rede social Edmodo e não tiveram dificuldades em encontrar os links (considerando que os mesmos os criaram para suas atividades planejadas). O uso do Edmodo foi considerado fácil pelos professores $(96,3 \%$ ) e alunos $(94,6 \%)$, que atribuíram em parte à sua semelhança com a rede social Facebook. De fato o Edmodo tem um layout que facilita a interação entre o professor e aluno, e remete as características do Facebook.

No que se refere à resolução de atividades utilizando o Edmodo, o gráfico 2 apresenta as respostas dos estudantes.

Gráfico 2 - Respostas do questionário em relação a resolução das atividades no Edmodo.

\section{Respostas dos estudantes}

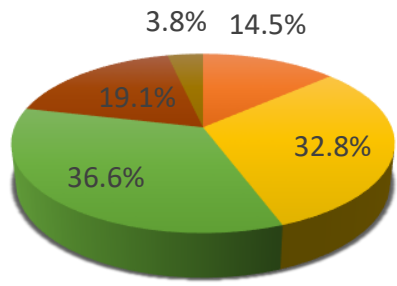

só, sem auxilio de nenhum recurso

—Consultando sites, blogs, redes sociais, etc

- Utilizava livros para resolver as atividades

—Consultava os amigos que participavam também das atividades do Edmodo

Outros

(Fonte: Própria) 
As respostas dos estudantes refletem algumas competências descritas por Moore (1993) presentes na teoria da distância transacional. A autonomia é a mais evidente, quer seja quando os estudantes respondem as atividades sozinhos $(14,5 \%)$, ou por consultas na Internet $(32,8 \%)$, ou por utilização de livros $(36,6 \%)$. Quanto maior a distância transacional, mais o aluno exercerá essa autonomia (LEITE, 2015), logo, atividades no Edmodo podem incentivar estudantes mais autônomos no processo de sua aprendizagem. Ademais, 19,1\% dos estudantes consultavam os amigos para resolverem as atividades no Edmodo, aqui observamos outra característica da teoria da distância transacional, por ocorrer entre indivíduos num ambiente que possui característica especial de ambos estarem separados um do outro. Essa separação "afeta profundamente tanto o ensino quanto a aprendizagem" (LEITE, 2015, p. 130). Nas atividades realizadas pelos alunos, a RSE pode substituir o uso de "listas de exercícios", o professor elaborava seu próprio material e disponibilizava no Edmodo, assim podendo acompanhar as atividades de seus alunos. Cabe ressaltar que, os professores elaboraram as atividades no Edmodo, portanto, desconsideramos suas respostas para esta questão.

A partir do questionamento "Quais contribuições você acredita que o Edmodo proporcionou?" observamos diversos relatos favoráveis ao uso do Edmodo. Para ilustrar vejamos algumas colocações por parte dos professores:

P1 - "um ambiente que permite organizar uma dinâmica diferente, além da praticidade, me ajudou no feedback com meus alunos quando resolviam as atividades ou debatíamos sobre os conteúdos discutidos ou a serem discutidos. Percebi que os diálogos no Edmodo tornaram o processo de ensino e aprendizagem mais construtivo".

P16 - "uso simples e parecido com o facebook fez com que meus alunos participassem mais das atividades".

P20 - "Ele permite o envio de conteúdos atualizados sobre as discussões em sala de aula, sem a necessidade de organizar um material e levar para a escola".

P23 - "a possibilidade de acompanhamento do desenvolvimento dos alunos durante o semestre".

A resposta de P1 leva-nos a considerar a importância do feedback discutida por Cushing e colaboradores (2011). Eles descobriram que as habilidades de consciência a educação podem ser melhoradas, dando feedback construtivo através da observação de pares. Também pode ser aplicado na consciência das competências linguísticas, deixando os colegas dar feedback positivo e construtivo durante a atividade de aprendizagem. Depois de aceitar o feedback, os estudantes terão oportunidade de rever seu trabalho, considerando as sugestões do professor e de colegas. É possível também relacionar a resposta com um dos princípios do Conectivismo, na qual a aprendizagem e conhecimento apoiam-se na diversidade de opiniões e posições, permitindo a seleção do melhor enfoque. As opiniões de P16, P20 e P23 corroboram a ideia de que o Edmodo facilita a interação entre os envolvidos e possibilita o acompanhamento do processo de construção do conhecimento dos alunos. Além disso, nessas respostas observamos que a atualização do conhecimento nas atividades no Edmodo pode ser descrita como um dos princípios conectivistas de aprendizagem (SIEMENS, 2004). É notório também a prática do ensino híbrido presente nessas respostas. Para os alunos, obtivemos diversas respostas, algumas foram: 
A12 - "foi divertida na aprendizagem do assunto, me fez querer buscar mais por conhecimento, sobre assuntos propostos pelo professor de química, e também da realização das provas de unidade do colégio".

A64 - "Aprender o conteúdo de uma forma mais agradável do que estudar com livros, caderno e fichas. Me ajudou muito, me deu muitas oportunidades de aprendizagem".

A79 - "As atividades conseguiram tirar minhas duvidadas".

A106 - "É mais interessante responder as atividades pelo site, acho que motiva mais o aluno em relação a isso. Ele me fez pesquisar mais, ler mais, me tornou mais comunicativa na sala de aula".

A129 - "Contribuiu muito porque ele é um site de atividades fácil de se utilizar, para que eu fizesse uma revisão para as avaliações escolares".

As respostas desses alunos revelam os benefícios no uso do Edmodo quanto a resolução de exercícios, compreensão dos conteúdos, facilidade na aprendizagem. É importante notar que algumas das respostas dos estudantes estão presentes nas propostas do conectivismo, em que a aprendizagem ocorre como parte de uma rede social, que o conhecimento está nas redes e que aprender e conhecer são processos contínuos, sendo importante manter as conexões para facilitar a aprendizagem contínua dos estudantes (SIEMENS, 2004; LEITE, 2014). A aprendizagem conectada é também evidenciada nas respostas dos estudantes, pois percebe-se o interesse quando eles estão aprendendo, quando tem seus pares e mentores compartilhando do mesmo interesse e na presença de uma aprendizagem mais ativa (ITO et al., 2013; CORNWELL; CORNWELL, 2006). Ademais, no Edmodo a teoria da distância transacional é presente, tanto nos aspectos de motivação e autonomia, bem como nas interações aluno-conteúdo, professor-aluno, aluno-aluno, sendo possível também interações professorprofessor e professor-pais.

Com a intencionalidade de verificar a opinião sobre os conteúdos discutidos no Edmodo, os professores e alunos corroboram com a ideia de que as atividades desenvolvidas foram apropriadas. Nesse sentido, P1 destaca que os conteúdos "completavam os assuntos discutidos em sala e possibilitava um tempo maior para a resolução das atividades" e P5 afirma que é "um reforço a aula, pois implica com que o aluno fique por dentro do assunto". Na opinião de A74 os "assuntos eram necessários para aprender o conteúdo, eram muito interessantes, bem interativos. Achei excelente, contribuiu bastante para o meu aprendizado" e de A110 "o professor discutia os assuntos e depois completava com mais informações ajudando a compreender". É preciso destacar que quando um assunto é relevante e significativo para alguém, melhores resultados de aprendizagem são atingidos, assim complementa o pensamento de que um indivíduo atinge o seu potencial quando é capaz de conectar seus interesses com o estudo acadêmico. Além disso, as respostas remetem as considerações da aprendizagem conectada, na qual "a aprendizagem emerge das relações sociais e do contexto cultural do aprendiz, e que a tecnologia é o suporte para o alcance dos resultados" (LEITE, 2015, 123). Contudo, é importante destacar que A96 considerou que os conteúdos eram "normais, são os mesmos discutidos em sala de aula com o professor!". Essa consideração deve ser analisada com atenção, pois o uso das tecnologias não substitui o papel do professor. Nesse contexto, o professor ao incorporar o uso das tecnologias em sua prática pedagógica deve levar em conta os aspectos 
instrucionais (MOORE; KEARSLEY, 2013), comunicacionais, interativos (BELUCE; OLIVEIRA, 2016; BROD; RODRIGUES, 2016) e didáticos, caso contrário, será apenas a "substituição" de uma ferramenta antiga (o quadro, por exemplo) por uma nova ferramenta (o computador, o celular, etc) sem uma efetiva mudança na prática docente. É preciso destacar que no fórum, o professor acaba incorporando seu típico monólogo, recorrente em suas aulas, afastando os alunos de participarem efetivamente do processo de aprendizagem, além de não articularem os conteúdos discutidos em sala de aula, transformando num característico ambiente de transmissão de informações. Os professores diante das tecnologias devem estar "capacitados para ensinar em ambientes com os mais diversos recursos didáticos" (LEITE, 2015, p. 25), assim, no Edmodo a mera utilização da rede social como reprodução das atividades ocorridas em sala de aula não deve motivar e/ou proporcionar novas experiências no processo de ensino e aprendizagem.

Considerando a participação do professor no Edmodo, os alunos em sua maioria $(96,9 \%)$ consideraram satisfatória. É consenso que quanto mais o professor interaja nas atividades síncrona e assíncrona, o interesse do aluno aumenta consideravelmente. Essa interação é potencializada pelo compartilhamento e organização das informações (O'REILLY, 2005). Moore e Kearsley (2013) destacam que para um bom desempenho em atividades on-line, os professores devem buscar uma relação pessoal, empatia com os alunos e motivação intrínseca (não extrínseca). O uso da RSE tem proporcionado algumas mudanças no comportamento dos estudantes e do professor, na qual destacamos:

(a) a comunicação, em que no modelo tradicional de ensino ocorria somente numa direção, a do professor para o aluno. No Edmodo a comunicação ocorre em múltiplas direções, principalmente entre os alunos, exigindo do professor um trabalho de direcionamento e estabelecimento de fronteiras, de tal forma que desvios dos objetivos planejados para a disciplina sejam evitados;

(b) a descontinuidade do acesso as informações disponíveis no ambiente de aprendizagem. Boa parte das atividades realizadas foram assíncronas, rompendo com o costume das discussões ocorrerem apenas em momentos presencias, na qual o professor fala sobre o assunto e o aluno debate apenas naquele momento;

(c) a avaliação, em que o papel do professor nesse processo exige algumas mudanças nos instrumentos avaliativos, conduzindo ao repensar os métodos de avaliação e exigindo muito mais dos formadores.

\section{PROPOSTAS DE USO DO EDMODO}

Durante os seminários nas disciplinas de IEQ e IQE, os discentes consideraram situações que poderiam utilizar o Edmodo em sua prática docente. Das propostas apresentadas, foi acentuada a atenção que esses conferiram para a interação entre o professor e os alunos. Stahl e colaboradores (2008) descrevem sobre a interação colaborativa, que ocorre quando indivíduos na realização de um propósito de interesse comum trabalham juntos. Os discentes enfatizaram o uso do chat e dos fóruns no Edmodo, para tirar dúvidas, acompanhar os estudantes nas atividades propostas, entre outras possibilidades. Essas propostas podem ser caracterizadas como uma interação colaborativa. Outras colocações são destacadas: 
A5 - "[...] lançando desafios para a maior interação do aluno no Edmodo e impulsionar o aluno a ficar mais atento para as curiosidades da matéria abordada, tornando-o mais ativo".

A16 - "[...] utilizar após a realização de uma prova, em que o aluno faria novamente a prova no Edmodo, ajudando a reforçar ou corrigir suas respostas na prova presencial".

A18 - "[...] realizar quizzes com os alunos, acompanhando a atividade pelo chat ou pelo fórum e fazer atividade com todos on-line, avaliando de forma diagnóstica e precisa".

A81 - "[...] aplicar questionários com os conteúdos extras, específicos e relevantes, e que os alunos produzissem vídeos como respostas as atividades do professor".

A127 - "[...] usar apenas assuntos reduzidos e simplificados servindo de complemento para os demais temas discutidos em sala. O uso de imagens, infográficos, vídeos e pequenos textos informativos seria muito importante para a criação de uma página leve e casual".

Tais propostas apresentam possíveis ocasiões de uso do Edmodo, em que os três tipos de interação podem ocorrer: Interação aprendente/conteúdo, Interação aprendente/instrutor e Interação aprendente/aprendente (MOORE, 1993). As respostas indicam a presença da distância transacional, na qual os alunos recebem instruções e orientação de estudo por meio do diálogo com o professor. Alguns princípios da aprendizagem conectada (CORNWELL; CORNWELL, 2006) é observado nas sugestões dos discentes A18, A5 e A81, respectivamente, quando consideram que a avaliação deve ser melhorada profundamente no processo de ensino e aprendizagem, que ela deve se tornar mais ativa, e que a aprendizagem ocorra por meio de conteúdos da mais alta qualidade, atual e relevante. $O$ ensino híbrido também pode ser observado nas sugestões destes alunos. Cabe ressaltar que, no Edmodo, o professor não é considerado o único responsável por definir, gerar ou organizar o conteúdo, pois conta também com a colaboração dos estudantes, característica do conectivismo (SIEMENS, 2004).

Por fim, consideramos que o professor deve levar em consideração a aprendizagem de técnicas especiais utilizando as tecnologias para a comunicação no ensino. As técnicas para atingir seus objetivos variam de acordo com a tecnologia utilizada. Silva e colaboradores (2016) destacam atividades conjuntas como relevantes, ao passo que visam a reflexão sobre a qualidade da formação e a possibilidade de interação entre os envolvidos. Um dos principais papéis do professor no uso do Edmodo é facilitar a interação, pois a participação dos alunos é um requisito básico em ambientes virtuais de aprendizagem para que eles possam ser bem-sucedidos. Ademais, Souza e Schneider (2016) refletem sobre o uso das tecnologias digitais na prática docente, na perspectiva de estarem presentes desde a formação inicial. Considerando que boa parte da formação inicial de professores de química é negligenciada no que se refere ao uso das tecnologias no ensino, e quando ocorrem discussões neste sentido, não observamos qualquer evidência concreta de que esses professores colocam em prática o que foi visto em suas formações. Dentre tantas questões relacionadas a essa problemática, Souza e Schneider (2016) consideram fundamental refletir sobre os métodos, as práticas e as didáticas específicas para a utilização das tecnologias digitais nos cursos de formação de professores. 


\section{CONSIDERAÇÕES FINAIS}

É perceptível que uma das situações que mais empolgam quem acompanha práticas utilizando as tecnologias no ensino é ver docentes e discentes usando criativamente recursos didáticos digitais em suas turmas. Isso mostra que, de maneira relativamente simples, é possível inovar com o que se tem disponível - e isso inclui redes sociais, que em alguns casos é considerada uma concorrente pela atenção em sala de aula. As redes sociais têm uma inegável utilidade para a educação formal, ainda que sua maior realização consista em estabelecer um vínculo que a une com a informal (HARO, 2010). Esta união produz um favorecimento no processo educativo.

Ao refletir sobre a interação nos ambientes on-line, consideramos importante que os professores promovam atividades que valorizem o feedback de seus estudantes, desde que sejam acompanhados de referenciais pedagógicos claros. Cabe ressaltar que, no uso das redes sociais o professor deve propor estratégias para que os recursos didáticos digitais não sejam meras substituições das aulas presenciais, mas que sejam complementos a sua prática docente e que "nem tudo que é tecnologicamente viável e pertinente em termos educacionais é realizável em todos os contextos educacionais" (LEITE, 2015, p. 28). As opções que as redes sociais dispõem, permitem que suas aplicações sejam utilizadas por docentes de inúmeras maneiras.

Os resultados refletem positivamente para o uso do Edmodo como uma ferramenta no processo de ensino e aprendizagem de química. Contudo é preciso o engajamento dos alunos e o planejamento dos professores quanto ao uso dessa ferramenta. Referente aos professores, foi possível conhecer aspectos importantes sobre sua apropriação no Edmodo. Também foi possível perceber a necessidade de uma formação continuada a esses professores a respeito do uso das tecnologias no ensino. Para os discentes, o uso do Edmodo foi promissor considerando seu primeiro contato com essa rede social. Eles participaram e compartilharam suas opiniões no uso da RSE, além de indicarem que sua aprendizagem não fica restrita a uma simples conglobação de informações soltas e desconectadas. Além disso, a presença de características do conectivismo, da teoria da distância transacional e da aprendizagem conectada reforçam os resultados apresentados.

Para tanto, o Edmodo possui características próprias e específicas que promovem mudanças no comportamento de professores e estudantes, além disso confere ao ensino híbrido e ao aprendizado combinado uma flexibilidade que dificilmente pode ser superada. Durante a pesquisa, as atividades no Edmodo facilitaram a aprendizagem do aluno por meio do ensino on-line, fornecendo uma experiência de aprendizagem integrada (HORN; STAKER, 2015), ou seja, por meio do ensino híbrido, além dos professores complementaram suas aulas presenciais utilizando a web (aprendizado combinado). À medida que mais professores incorporem em sua prática docente o conceito de ensino híbrido, novas metodologias pedagógicas devem aproximar cada vez mais o real e o virtual.

Uma das vantagens do Edmodo é a privacidade e o foco educacional, além disso, há escolas que bloqueiam as Redes Sociais não permitindo sua utilização durante o período de aula. Acreditamos que a restrição de uso não é seja o melhor caminho tomado pelas instituições de ensino. É preciso que essas instituições incorporem as redes sociais como um recurso que apresenta forte ligação com o 
cotidiano dos discentes. Um bom planejamento e aplicação pode contribuir fortemente para envolver os alunos na construção de seu conhecimento, relacionando com atividades desafiadoras e que são conectadas ao cotidiano do aluno. A criação e inovação também estão presentes no Edmodo. Neste sentido, o professor pode criar exercícios baseados em alguns modelos disponíveis, saindo da rotina de sala de aula, habitual de muitos alunos.

A Rede Social Edmodo ainda é "recente" no Brasil, são poucas as comunidades existentes em língua portuguesa. Também é observado um número pequeno de artigos científicos sobre esta rede social, relatando uma baixa familiaridade dos professores no Brasil com esta. O que infere que outras pesquisas podem ser desenvolvidas com esta rede educacional e que em breve seus resultados serão divulgados. Acreditamos que a RSE tem grande potencial para auxiliar no processo de ensino e aprendizagem, como um ambiente virtual gratuito em que a interação entre o professor e os alunos é acentuada. A rede pode apresentar uma característica multissensorial que pode ser explorada, sendo necessário ao professor fazer a antecipação da ação do sujeito, ou seja, quais estratégias de aprendizagem serão utilizadas para a aprendizagem do aluno. É fato que a motivação é o primeiro passo para o engajamento. Existem muitas formas de usar as redes sociais na educação, esta pesquisa mostra apenas algumas possibilidades. 


\title{
Blended Learning using Edmodo Social Network: an exploratory study on the educational potentialities for the chemistry teaching
}

\begin{abstract}
The Edmodo Social Network (ESN) has its own specific features that promote changes in teacher behavior and students. The research reports the experience of 27 chemistry teachers (high school and higher education) and 131 undergraduate students of the chemistry course, appropriating the Edmodo. The use of ESN by these teachers came through the blended teaching model. Through this model, students performed the activities during the discipline. The results show a favorable posture of the teachers and students face to utilization of the Edmodo in classroom. Principles of connectivism, connected learning and Theory of Transactional Distance are reported. We conclude that the use of ESN, incorporated strategies in blended learning, has great potential to assist in the process of teaching and learning, besides being a free virtual environment in which the interaction between the teacher and the students is enhanced.
\end{abstract}

KEYWORDS: ICT. Social Network. Blended learning. Edmodo. 
1 Disponível em: http://www.Edmodo.com.

2 Disponível em: https://goo.gl/nfnqrh.

\section{REFERÊNCIAS}

ANDERSON, T.; DRON, J. Three generations of distance education pedagogy. International Review of Research in Open and Distance Learning, v. 12, n. 3, p. 80-97, 2011.

ARROIO, A.; GIORDAN, M. O vídeo educativo: aspectos da organização do ensino. Química Nova na Escola, v. 24, n. 1, p. 8-11, 2006.

BELUCE, A. C.; OLIVEIRA, K. L. Escala de estratégias e motivação para aprendizagem em ambientes virtuais. Revista Brasileira de Educação, v. 21, n. 66, p. 593-610, 2016.

BENITE, A. M. C.; BENITE, C. R. M. O computador no ensino de química: Impressões versus realidade. Em Foco as escolas públicas da Baixada Fluminense. Ensaio Pesquisa em Educação em Ciências, v. 10, n. 2, p. 1-20, 2008.

BONK, C.; GRAHAM, C. R. The handbook of blended learning: global perspectives, local designs. San Francisco: Wiley, 2006.

BRASIL. Ministério da Educação. Decreto 5.622 de 19 de dezembro de 2005, 2005.

BRASIL. Ministério da Educação. Portaria № 2.253 de 18 de outubro de 2001, 2001.

BROD, F. A. T.; RODRIGUES, S. C. O conversar como estratégia de formação contínua na tutoria da educação profissional a distância. Revista Brasileira de Educação, v. 21, n. 66, p. 631-652, 2016.

CORNWELL, W. R.; CORNWELL, J. R. Connected learning: A framework of observation, research and development to guide the reform of education. Breckenridge, CO: The Center for Internet Research, 2006. 
COUTINHO, C. P. A qualidade da investigação educativa de natureza qualitativa: questões relativas à fidelidade e validade. Educação Unisinos, v. 12, n. 1, p. 5-15, 2008.

CUSHING, A.; ABBOTT, S.; LOTHIAN, D.; HALL, A.; WESTWOOD, O. Peer feedback as an aid to learning--what do we want? Feedback. When do we want it? Now! Medical Teacher, v. 33, n. 2, p. 105-112, 2011.

DEWEY, J.; BENTLEY, A. F. Knowing and the Known. Boston: Beacon Press, 1949.

EICHLER, M. L.; GONÇALVES, M. R.; SILVA, F. O. M.; JUNGES, F.; DEL PINO, J. C. Uma proposta para o desenho interdisciplinar de ambientes virtuais de aprendizagem de ciências. Revista Novas Tecnologias na Educação, v. 1, n. 2, p. 1-13, 2003.

GIL, A. C. Métodos e técnicas de pesquisa social. São Paulo: Atlas, 2008.

GOLDENBERG, M. A arte de pesquisar: como fazer pesquisa qualitativa em ciências sociais. Rio de Janeiro: Record, 2004.

GRAHAM, C. Blended learning systems: definition, current trends, and future directions. In: BONK, C.; GRAHAM, C. (Org.). The handbook of blended learning: global perspectives, local designs. San Francisco: Wiley, 2006.

HARA, N.; KLING, R. Students' frustrations with a web-based distance education course. First Monday, v. 4, n. 12, 1999.

HARO, J. J. Redes sociales en educación. Disponível em: http://jideharo.blogspot.com.br/2010/05/redes-sociales-en-educacion.html. Acesso em: 05/10/2016.

HORN, M. B.; STAKER, H. blended: usando a inovação disruptiva para aprimorar a educação. Porto Alegre: Penso, 2015.

ITO, M.; GUTIÉRREZ, K.; LIVINGSTONE, S.; PENUEL, B.; RHODES, J.; SALEN, K.; SCHOR, J.; SEFTON-GREEN, J.; WATKINS, S.G. Connected learning: An agenda for research and design. Irvine, CA: Digital Media and Learning Research Hub, 2013.

LEITE, B. S. M-Learning: o uso de dispositivos móveis como ferramenta didática no Ensino de Química. Revista Brasileira de Informática na Educação, v. 22, n. 3, 
LEITE, B. S. Tecnologias no ensino de química: teoria e prática na formação docente. Curitiba: Appris, 2015.

LEITE, B. S.; LEÃO, M. B. C. Contribuição da Web 2.0 como ferramenta de aprendizagem: um estudo de caso. Revista Brasileira de Ensino de Ciência \& Tecnologia, v. 8, n. 4, p. 288-315, 2015.

LÜDKE, M.; ANDRÉ, M. E. D. A. Pesquisa em educação: abordagens qualitativas. São Paulo: EPU, 1986.

LUNDEBERG, M. A.; MOCH, S. D. Influence of social interaction of cognition: Connected learning in Science. The Journal of Higher Education, v. 66, n. 3, p. 312-335, 1995.

MATTAR, J. Aprendizagem em ambientes virtuais: teorias, conectivismo e MOOCs. Revista digital de tecnologias cognitivas, n. 7, p. 21-40, 2013.

MERCADO, L. P. L. Formação continuada de professores e novas tecnologias. Maceió: EDUFAL, 1999.

MOORE, M. Theory of Transactional Distance. In: KEEGAN, D. Theoretical Principles of Distance Education. London: Routledge, 1993. p. 22-38.

MOORE, M. Three Types of Interaction. American Journal of Distance Education, v. 3, n. 2, p. 1-7, 1989 .

MOORE, M.; KEARSLEY, G. Educação a distância: sistemas de aprendizagem online. São Paulo: Cengage Learning, 2013.

MOORE, M.; KEARSLEY, G. Educação a distância: uma visão integrada. São Paulo: Thomson, 2007.

O'REILLY, T. What is Web 2.0. Design patterns and business models for the next generation of software, 2005. Disponível em: http://www.oreillynet.com/pub/a/oreilly/tim/news/2005/09/30/what-is-web20.html. Acesso em 18/07/2016.

PEREIRA, L. L. S.; BENITE, A. M. C. Redes sociais como espaço de interações discursivas sobre Formação de professores de ciências para a educação inclusiva. 
RAUPP, D.; EICHLER, M. L A rede social Facebook e suas aplicações no ensino de química. Revista Novas Tecnologias na Educação, v. 10, n. 1, p. 1-10, 2012.

REIS, F. L. Do ensino presencial ao ensino a distância no contexto universitário. Revista Científica da FAI, v. 9, n. 1, p. 81-94, 2009.

RICHARDSON, R. J. Pesquisa social: métodos e técnicas. São Paulo: Atlas, 1999.

ROBLYER, M. D. Integrating educational technology into teaching. Ohio: Pearson Education, 2006.

ROBLYER, M. D.; WIENCKE, W. Design and use of a rubric to asses and encourage interactive qualities in distance courses. The American journal of distance education, v. 17, n. 2, p. 77-98, 2003.

ROSA, M. P. A. Química e as tecnologias digitais: investigação sobre as representações docentes. Dissertação (Mestrado em Educação). Programa de Pós-Graduação do Mestrado em Educação, Universidade de Caxias do Sul, 2012.

SCHWARTZ, K. B. Clinical reasoning and new ideas on intelligence: Implications for teaching and learning. American Journal of Occupational Therapy, v. 45, n. 11 , p. 1033-1037, 1991.

SIEMENS, G. Connectivism: A Learning Theory for the Digital Age. Instructional Technology and Distance Education, v. 2, n. 1, p. 3-10, 2004.

SILVA, J. R. N.; SILVA, A. P.; MOREIRA, C. C.; PEREIRA, J. F. Contribuições de um planejamento conjunto entre as modalidades presencial e a distância na constituição de uma disciplina de prática de ensino de física. Revista Brasileira de Ensino de Ciência \& Tecnologia, v. 9, n. 1, p. 1-25, 2016.

SOUZA, A. A. N.; SCHNEIDER, H. N. Tecnologias digitais na formação inicial docente: articulações e reflexões com uso de redes sociais. ETD - Educação Temática Digital, v. 18, n. 2, p. 418-436, 2016.

SOUZA, C. L.; FRANCISCO JUNIOR, W. E.; MARTINES, E. A. L. M. Vídeos educativos para o ensino de química: alguns apontamentos sobre o telecurso 2000. In: VIII ENCONTRO NACIONAL DE PESQUISA, 2011, Anais... - Campinas, 2011.

STAHL, G.; KOSCHMANN, T.; SUTHERS, D. Aprendizagem colaborativa com Página | 229 suporte computacional: Uma perspectiva histórica. Boletim Gepem, v. 53, p. 1142, 2008. 
TORI, R. Cursos híbridos ou blended learning. In: FORMIGA, M; LITTO, F. Educação a Distância: o estado da arte. São Paulo: Pearson Education, 2009. p. 121-128.

VAZ, W. F.; SOARES, M. H. F. B. Análise de comunidades de Química da Rede Social Orkut: comunicação, conceito e linguagem no Ensino de Química. Revista Brasileira de Pesquisa em Educação em Ciências, v. 14, n. 1, p. 101-123, 2014

Recebido: 2016-10-25

Aprovado: 2017-03-22

DOI: $10.3895 /$ rbect.v10n3.4873

Como citar:

LEITE, B. S. Ensino híbrido utilizando a Rede Social Edmodo: um estudo exploratório sobre as potencialidades educacionais para o Ensino de Química. Revista Brasileira de Ensino de Ciência e

Tecnologia, v. 10, n. 3, p. 206-230, 2017. Disponível em: . Acesso em: xxx

Correspondência:

Bruno Silva Leite - brunoleite@ufrpe.br

Direito autoral: Este artigo está licenciado sob os termos da Licença Creative Commons-Atribuição 4.0 Internacional. 